\title{
CHILDREN WITH EMOTIONAL AND BEHAVIORAL DISORDERS IN SAUDI ARABIA: A TEACHER PRELIMINARY SCREENING
}

\author{
*Hassan Maajeeny
}

\begin{abstract}
Children with emotional and behavioral disorders, although a distinct category of children with special needs, are neither identified nor served in Saudi Arabia. The aim of this study was to extend previous efforts to estimate the prevalence of emotional and behavioral disorders among children in Saudi Arabia in order to evaluate the need for intervention services. In the current study, teachers of students aged 4-17 years in Saudi Arabia were surveyed using the Strengths and Difficulties Questionnaire - Teacher version. The findings of the study suggest that students with emotional and behavioral disorders in Saudi Arabia may account for almost $25 \%$ of the population of school students between the ages of 4 and 17. The findings also revealed that teachers complained the most about behaviors that are related to conduct followed by problems with peer relationship.
\end{abstract}

Keywords: Special Education, Prevalence Screening, Emotional/Behavioral Disorders, Teachers, Saudi Arabia.

\section{Introduction}

Children come to schools from different backgrounds with different social, emotional, and academic needs. This variance places significant pressure on teachers to ensure those needs are addressed (Sprague \& Perkins, 2009; Walker, 2004). If those needs are not met, students may face negative life outcomes including school dropout, depression, substance abuse, divorce, unemployment, and/or confrontation with justice and mental health systems (Harrison, Vannest, \& Raynolds, 2013). Research shows that children who display problem behaviors are more likely to experience chronic behavioral and emotional problems during adolescence and adulthood (Caspi, Henry, McGee, Moffitt, \& Silva, 1995; Moffitt, Caspi, Dickson, Silva, \& Stanton, 1996; Molina \& Pelham, 2003). Fortunately, research also shows that early intervention services can prevent the progression of problem behaviors toward chronicity (Cooper, Masi, \& Vick, 2009).

These needs can be addressed through careful assessment and planning of behavioral interventions. Before interventions for children with emotional and behavioral disorders (E/BD) are planned and implemented, it is important to define and identify the disorders appropriately. Once a definition is accepted, it will reflect on how we conceptualize the problem and what intervention strategies we consider appropriate (Kauffman \& Landrum, 2013). Without an operational definition, it is difficult to screen children for E/BD. Screening is a critical component of the process of delivering the appropriate services for children with $\mathrm{E} / \mathrm{BD}$ because once those children are identified, it is possible to decrease the wide range of adverse outcomes that children might experience in their lives (Harrison et al., 2013).

In 2004, Abdel-Fattah et al. conducted a screening study to identify the percentage of children who have E/BD in Saudi Arabia. However, the sample included in the study consisted only of male students in one school in the city of Taif, Saudi Arabia. Although the findings have limited generalizability, the researchers found that $8.3 \%$ of the population of that school were identified with E/BD. Assuming the percentage to be correct and generalizable to the whole nation of Saudi Arabia, the rate of 8.3 represents almost .5 million children in schools who might be diagnosed with E/BD. With a $2.1 \%$ growth of the Saudi population, 
according to the General Authority for Statistics (2016), the number of children with E/BD would be expected to increase by 10,000 students per year. The rate of $8.3 \%$ of the school population is alarmingly high, necessitating immediate attention from professionals and the Saudi Government.

In Saudi Arabia, children with E/BD are recognized as a distinct category of special education despite the insufficiency of efforts to identify and serve those children. The lack of enough research implies a need for an intensive investigation into the area of E/BD starting with the task of defining and measuring the magnitude of the problem of $\mathrm{E} / \mathrm{BD}$ in Saudi Arabia. It is important to determine the prevalence of $\mathrm{E} / \mathrm{BD}$ among children in Saudi Arabia before discussing the need for interventions and services for this population (Conroy \& Brown, 2004). As an initiative to estimate the prevalence of $\mathrm{E} / \mathrm{BD}$ in Saudi Arabia, Maajeeny (2018) conducted a screening study surveying parents of children between the ages of 4 and 17 in Saudi Arabia and results showed that $20 \%$ of the population might meet the criteria for E/BD. For these results to be conclusive, the results should take into consideration perspectives of multiple informants including, parents, teachers, school administrators, and children themselves.

This study aimed to extend the efforts of Maajeeny (2018) to estimate the prevalence of E/BD is Saudi Arabia in order to identify the need for intervention services for those children by surveying teachers who serve students between the ages of 4 and 17 in both general and special education settings.

The term emotional/behavioral disorders (E/BD) is one of a variety of terms commonly used to refer to children who exhibit unacceptable forms of either internalizing or externalizing behaviors. The term "serious emotional disturbance" refers to a diagnosed mental health problem that prevents children from functioning socially, emotionally, and academically. It is an official term used by state and federal agencies to identify a population of children who have significant emotional and behavioral problems and who have a high need for services (Brauner \& Stephens, 2006; Kauffman \& Landrum, 2013). Other terms, such as antisocial behaviors, emotional disturbance, problematic behaviors, severe emotional disturbance (SED), and disruptive behaviors, are also used to refer to behaviors exhibited within the range of $\mathrm{E} / \mathrm{BD}$ (Forness \& Knitzer, 1992). Over the years, many definitions have been proposed to describe and specify the phenomena of E/BD. Those definitions were proposed based on the purposes they serve for the professions by which they were introduced. For example, psychiatrists have developed a definition of $\mathrm{E} / \mathrm{BD}$ for diagnostic purposes that helps them refer a child to the appropriate therapeutic program, as will be discussed below. On the other hand, educators define $\mathrm{E} / \mathrm{BD}$ based on its implications for a child's academic performance and the effects of those behaviors on the continuity of the educational process of the child and those who are around the child (Kauffman \& Landrum, 2013).

The official definition of emotional disturbance adopted by all school districts in the United States of America is the federal definition proposed by the Individuals with Disabilities Education Act (IDEA, 2004). According to the IDEA (2004):

Emotional disturbance means a condition exhibiting one or more of the following characteristics over an extended period and to a marked degree that adversely affects a child's educational performance:

a) An inability to learn that cannot be explained by intellectual, sensory, or health factors;

b) An inability to build or maintain satisfactory interpersonal relationships with peers and teachers;

c) Inappropriate types of behavior or feelings under normal circumstances;

d) A general pervasive mood of unhappiness or depression;

e) A tendency to develop physical symptoms or fears associated with personal or school problems.

f) Emotional disturbance includes schizophrenia. The term does not apply to children who are socially maladjusted, unless it is determined that they have an emotional disturbance under paragraph (c)(4)(i) of this section.

Dissatisfied with the IDEA's definition of E/BD, the Council for Children with Behavioral Disorders (CCBD) and other professional advocates cooperated to form the National Mental Health and Special Education Coalition, which offered an alternative to the federal definition (Kauffman \& Landrum, 2013). The Coalition proposed the following definition:

(i) The term emotional or behavioral disorder means a disability characterized by behavioral or emotional responses in school so different from appropriate age, culture, or ethnic norms that they adversely affect educational performance. Educational performance includes academic, social, vocational, and personal skills. Such a disability (a) is more than a temporary, expected response to stressful events in the environment; (b) is consistently exhibited in two different settings, at least one of which is school-related; and (c) is unresponsive to direct intervention in general education or the child's condition is 
such that general education interventions would be insufficient.

(ii) Emotional and behavioral disorders can coexist with other disabilities.

(iii) This category may include children or youth with schizophrenic disorders, affective disorders, anxiety disorder, or other sustained disorder of conduct or adjustment when they adversely affect educational performance in accordance with section (i) (Forness \& Knitzer, 1992, p. 13).

The process of accurately estimating the prevalence of $\mathrm{E} / \mathrm{BD}$ is difficult due to the lack of a comprehensive definition of a minimum level of functional impairment in some or all domains for an agreed-upon duration (Brauner \& Stephens, 2006). However, many efforts have been devoted to estimating the prevalence of E/BD. Recently, Maajeeny (2018) reported that children with E/BD may represent $20 \%$ of the general population of children between the ages of 4 and 17 in Saudi Arabia. According to the latest count by the U.S. Department of Education (2016), children with E/BD represent $5.9 \%$ of children with disabilities who are served under the IDEA. This estimate may not be definitive because it excluded children who were not identified or served. Researchers have been occupied with determining an estimated prevalence of E/BD across the world. In the United States of America, Pastor, Reuben, and Duran (2012) concluded that children with E/BD represent $7 \%$ of the children between the ages of 4 and 17 in the United States of America. While this estimate may be conservative, Owens et al. (2015) found that $15 \%$ of kindergarten children can be classified as having E/BD. In their review, Brauner and Stephens (2006) found that across studies, estimates of the prevalence of E/BD in the United States of America ranged from 5\% to $26 \%$. Studies in other nations also reveal a wide range of estimates. In Pakistan, estimates of the prevalence of $\mathrm{E} / \mathrm{BD}$ range from $34 \%$ to $42 \%$ (Hussein, 2008; Syed, Hussein, \& Mahmud, 2007). In the Netherlands, a study identified $13.2 \%$ of Moroccan-Dutch students between the ages of 9 and 16 as having E/BD (Adriaanse, van Domburgh, Zwirs, Doreleijers, \& Veling, 2015). In Germany, the prevalence is estimated to be $16 \%$ for kindergarten aged children (Fuchs, Klein, Otto, \& Klitzing, 2013) and $18.5 \%$ for schoolchildren between the ages of 6 and 16 (Woerner et al., 2002).

Children with E/BD frequently struggle in maintaining good academic standings. Nelson, Benner, Lane, and Smith (2004) found that children with $\mathrm{E} / \mathrm{BD}$ experience large academic achievement deficits across all content areas (i.e., mathematics, reading, and written language). Because of their behavior, children with E/BD frequently struggle in school and are more likely to fail and drop out of school. The educational policies of most nations encourage the placing of children with disabilities in the least restrictive environment. The goal is to put as many children with disabilities as possible in the general education system, adhering to the Salamanca Statement (United Nations Educational, Scientific, and Cultural Organization [UNESCO], 1994), which states that all children, including children with disabilities, must have the opportunity to be educated in the regular school. Children with E/BD have broad-based academic deficits that remain stable or even increase in severity over time (Lane, Kalberg, Lambert, Crnobori, \& Bruhn, 2010). Therefore, because they are considered the most challenging group to be handled in the general education classroom, children with E/BD are more likely to be placed in the most restrictive settings (i.e., separate schools and self-contained classrooms; Stoutjesdijk, Scholte, \& Swaab, 2012). This shows clearly that children with E/BD have different academic, behavioral, emotional, and social needs from children without E/BD.

Academic achievement has been an area of great concern to many parents of children with E/BD. When surveyed to identify their concerns about their children's difficulties, the highest proportion of parents reported significant deficiencies in learning or education (Fuchs et al., 2013). Parents reported hyperactivity/inattention in the borderline or abnormal range more frequently than other ranges of symptoms; thus, it is assumed that there is a strong relationship between increased levels of hyperactivity/inattention and problems in learning. The finding that $\mathrm{E} / \mathrm{BD}$ is related to learning difficulties is predictable because children with E/BD usually exhibit disruptive forms of behavior that impede their ability to learn and disrupt the learning environment, hindering other students' learning. Working with children with EBD is challenging and requires collaboration among school personnel, parents, and administrators (Maajeeny, 2019).

Although it may seem safe to conclude that E/BD and the associated risk factors are highly correlated with learning and academic difficulties, Trout, Nordness, Pierce, and Epstein (2003) found that research on the academic achievement of children with $\mathrm{E} / \mathrm{BD}$ has been conducted in psychiatric or residential settings, which limits the extent to which the results can be generalized to students served in the general education setting or other placements. Also, they found that most studies evaluated students' academic achievement through standardized tests, which may result in misidentification and misplacement of students. 
Finally, they found that the number of studies on the academic achievement of children with E/BD had dramatically decreased during the ten years before the review (i.e., from 1991 to 2000). This might be true when the study was published. However, many studies related to the academic status of children with E/BD were published afterward (e.g., Nelson et al., 2004; Lane et al., 2010; Stoutjesdijk, et al., 2012).

\section{Methods}

The current research investigates the characteristics of children between the ages of 4 and 17 as a subset of the population of Saudi Arabia. The participants of this study $(\mathrm{N}=658)$ were teachers of students who are between the ages of 4 and 17. The teacher's population of Saudi Arabia has been divided into five geographical clusters (i.e., western, eastern, northern, southern, and central). Around $76 \%$ of the participants were female teachers $(\mathrm{n}=499)$ while $24 \%$ were males $(\mathrm{n}=$ 159). Eighty-six percent of the participants work in general education setting while $14 \%$ in special education. Across the geographical regions, $63.4 \%$ reported from the western region $(n=417), 6.4 \%$ reported from the eastern region $(n=42), 8.2$ from the central region $(n=54), 3 \%$ from the northern region $(n=20)$, and $19 \%$ reported form the southern region $(\mathrm{n}=125)$. Regarding students, participants reported on behalf of $31.2 \%$ male students $(\mathrm{n}=205)$ and $68.8 \%$ female student $(\mathrm{n}=$ 453). Those children were between the ages of 4 and 17 with $18 \%$ in age 17 and $11 \%$ in age 10 while the rest are distributed across the remaining age groups.

According to the Saudi General Authority for Statistics, the entire teacher population of Saudi Arabia has recently been projected to be around 600,738 teachers. For the sample to be representative of the population, a large sample size was needed for the current research $(\mathrm{n}=384)$, based on a confidence interval of \pm 3 and a confidence level of $95 \%$. The only criterion for participation eligibility in the present study was being the teacher of a student between the ages of 4 and 17. Teachers were asked to complete a 25-item Likert-scale questionnaire about their student's behavior.

The present study utilized the teachers' version of the Strengths and Difficulties Questionnaire (SDQ), originally developed and published in English by Goodman (1997). The SDQ is a free brief behavioral screening questionnaire for children around the ages of 4-17 years. Validating the instrument on a British population, Goodman (2001) found that the SDQ had overall satisfactory psychometric properties (Cronbach $\alpha=.73$, crossinformant correlation mean $=0.34$, and retest consistency mean $=0.62$ ). Alyahri and Goodman (2006) translated and validated an Arabic version of the SDQ and concluded that it is a valid and reliable screening measure for mental health difficulties in young people.

The SDQ consists of 25 items that are divided into five scales: emotional symptoms, conduct problems, hyperactivity/inattention, peer relationship problems, and prosocial behavior. Each scale is measured by five items where respondents specify their level of agreement or disagreement on a symmetric true-not true scale (i.e., not true, somewhat true, and certainly true). After scoring, the questionnaire will provide seven outcomes: a total difficulty score (range 0-40).

\section{Findings and Discussion}

\section{Findings}

The number of responses on the SDQ was higher than expected $(\mathrm{N}=658)$. A reliability test of the SDQ resulted in an acceptable level of overall reliability (Cronbach $\alpha=.64$ ). The analysis of the results of the SDQ revealed an average of the total difficulties scores of $17(\mathrm{SD}=4.97)$. Based on the scoring guide of the SDQ, $24.6 \%$ of the sample scored in the "Very High" category $(n=162)$, $21.7 \%$ scored in the "High" category $(n=143)$, $24.2 \%$ were counted in the "Slightly Raised" category $(n=159)$, and the remaining $30 \%$ were the norm of the sample or categorized as "Close to Average" $(\mathrm{n}=194)$ (See Table A.1).

As for the scores on the subscales, on the Emotional Problems subscale, $19.6 \%$ of children scored in the "Very High" category $(\mathrm{n}=129), 19 \%$ scored in "High" $(\mathrm{n}=125), 18.2 \%$ scored in "Slight Raised" ( $\mathrm{n}=120)$, and $43.2 \%$ scored "Close to Average" ( $\mathrm{n}=284)$. On the Peer Relationship subscale, $21.3 \%$ of children scored in the "Very High" category $(\mathrm{n}=140), 23.3 \%$ scored in "High" $(\mathrm{n}=153), 44.7 \%$ scored in "Slight Raised" ( $\mathrm{n}=294)$, and $10.8 \%$ scored "Close to Average" ( $n=71)$. As for the Conduct Problems subscale, $35 \%$ of children scored in the "Very High" category $(\mathrm{n}=230), 20.5 \%$ scored in "High" $(\mathrm{n}=135), 22 \%$ scored in "Slight Raised" $(\mathrm{n}=145)$, and $22.5 \%$ scored "Close to Average" ( $n=148)$. On the ADHD subscale, $1.4 \%$ of children scored in the "Very High" category $(n=9), 3 \%$ scored in "High" (n = 20), 28.1\% scored in "Slight Raised" $(\mathrm{n}=185)$, and $67.5 \%$ scored "Close to Average" (n $=444$ ). Furthermore, on the Prosocial Behavior subscale, $11.7 \%$ of children scored in the "Very Low" category $(\mathrm{n}=77), 9.6 \%$ scored in "Low" ( $\mathrm{n}$ $=63), 20.5 \%$ scored in "Slight Lowered" $(n=135)$, and $58.2 \%$ scored "Close to Average" $(\mathrm{n}=383)$. 


\section{Discussion}

In the current study, teachers of students between the ages of 4 and 17 were surveyed by randomly choosing one of their students and responding to the SDQ questionnaire. Although the reliability test score is lower than most previous studies (i.e., Goodman, 2001; Maajeeny, 2018), the obtained score is still within an acceptable range. Examining the total difficulty scores, the percentages of students who scored in "Very High" and "High" are alarming. This indicate that almost $46 \%$ of students between the ages of 4 and 17 may meet the criteria to be diagnosed with $\mathrm{E} / \mathrm{BD}$ or may be at risk for the disorder. Those two categories indicate the need for additional assessment and determine the need for intervention services for children with $\mathrm{E} / \mathrm{BD}$ in the school system.

A high percentage (i.e.,35\%) of teachers responded to the survey complained about conduct problems followed by $21 \%$ complained about peer relationship issues among their students. In addition, 19.6 of students are reported to have emotional problems while, remarkably, only a small percentage of teachers complained of ADHD-related behaviors. These results reveal the types of behaviors that are most evident in the school environment. According to Maajeeny (2018) the most evident problematic behaviors indicated by parents were issues related to peer relationships. This is with alignment with the current study although teachers reported higher complains about conduct problems.

The results from the currents study, although not conclusive, provide valuable contribution to the effort of estimating the prevalence of children with E/BD in Saudi Arabia. It shows that teachers have the tendency to report about students they often struggle dealing with. This explains the high percentages in both the "Very High" and the "High" category within the total difficulty scores. In contrary to parents, teachers have a high number of students within the same age group in the classroom which directs their decision towards responding about the student whose behaviors are most disturbing to the educational process. Parents tend to report about their children with the designated age group regardless of their problem behaviors. In addition, parents complained the most about peer relationship problems (Maajeeny, 2018) compared to teachers, in the current study, who seem to struggle the most with conduct issues in the classroom. This pinpoints the behaviors that concern teachers the most in comparison to parents. Given these interpretations, school personnel and other professionals can plan prevention or intervention programs accordingly.

\section{Conclusion}

Even though the current study addressed an important inquiry estimating the prevalence of students with E/BD in the school setting, many other questions and inquiries have aroused. Given the discrepancies among the findings of Maajeeny (2018) and the current study, it is crucial to identify what criteria should be considered when estimating the prevalence and who are the informant who can accurately describe the phenomena and based on what. Teachers and parents complain about different patterns of problem behaviors. Therefore, some definitions of E/BD (e.g. Forness \& Knitzer, 1992) considered problem behaviors to be disturbing if they occur in more than one setting one of which is school. Identifying an accurate prevalence of $\mathrm{E} / \mathrm{BD}$ requires intensive efforts and investigation that may involve looking at the study sample in more than one setting with multiple informants.

\section{Table A.1}

Descriptive of the Strengths and Difficulties Questionnaire

\begin{tabular}{lllll}
\hline Outcome & $\begin{array}{l}\text { Close to } \\
\text { Average }\end{array}$ & $\begin{array}{l}\text { Slightly } \\
\text { Raised }\end{array}$ & High & $\begin{array}{l}\text { Very } \\
\text { High }\end{array}$ \\
\hline $\begin{array}{l}\text { Total } \\
\text { Difficulty } \\
\text { Score }\end{array}$ & $\begin{array}{l}194 \\
(30)\end{array}$ & $\begin{array}{l}159 \\
(24.2)\end{array}$ & $\begin{array}{l}143 \\
(21.7)\end{array}$ & $\begin{array}{l}162 \\
(24.6)\end{array}$ \\
$\begin{array}{l}\text { Emotional } \\
\text { Problems }\end{array}$ & 284 & 120 & 125 & 129 \\
Conduct & $143.2)$ & $(18.2)$ & $(19)$ & $(19.6)$ \\
Problems & $(22.5)$ & 145 & 135 & 230 \\
ADHD & 444 & 185 & $20.5)$ & $(35)$ \\
& $(67.5)$ & $(28.1)$ & & $(1.4)$ \\
Peer & 71 & 294 & 153 & 140 \\
Relationshi & $(10.8)$ & $(44.7)$ & $(23.3)$ & $(21.3)$ \\
\hline
\end{tabular}

Note. Count (Percentage)

\section{References}

1. Abdel-Fattah, M., Asal, A., Al-Asmary, S., AlHelali, N., Al-Jabban, T., \& Arafa, M. (2004). Emotional and behavioral problems among male Saudi schoolchildren and adolescents: Prevalence and risk factors. German Journal of Psychiatry, 7(1), 1-9.

2. Adriaanse, M., van Domburgh, L., Zwirs, B., Doreleijers, T., \& Veling, W. (2015). Schoolbased screening for psychiatric disorders in Moroccan-Dutch youth. Child and Adolescent Psychiatry and Mental Health, 9(1), 1-13.

3. Alyahri, A., \& Goodman, R. (2006). Validation of the Arabic strengths and difficulties questionnaire and the development 
and well-being assessment. Eastern Mediterranean Health Journal, 12(2), 138-146.

4. Brauner, C., \& Stephens, C. (2006). Estimating the prevalence of early childhood serious emotional/behavioral disorders: Challenges and recommendations. Public Health Reports, 121(3), 303-310.

5. Caspi, A., Henry, B., McGee, R., Moffitt, T., \& Silva, P. (1995). Temperamental origins of child and adolescent behavior problems: From age three to age fifteen. Child development, 66(1), 55-68.

6. Conroy, M., \& Brown, W. (2004). Early identification, prevention, and early intervention with young children at risk for emotional or behavioral disorders: Issues, trends, and a call for action. Behavioral Disorders, 29(3), 224-236.

7. Cooper, J. L., Masi, R., \& Vick, J. (2009). Social-emotional development in early childhood: what every policymaker should know. New York: National Center for Children in Poverty.

8. Forness, S., \& Knitzer, J. (1992). A new proposed definition and terminology to replace" serious emotional disturbance" in Individuals with Disabilities Education Act. School Psychology Review, 21(1), 12-20.

9. Fuchs, S., Klein, A., Otto, Y., \& Klitzing, K. (2013). Prevalence of emotional and behavioral symptoms and their impact on daily life activities in a community sample of 3 to 5year-old children. Child Psychiatry \& Human Development, 44(4), 493-503.

10. Goodman, R. (1997). The strengths and difficulties questionnaire: A research note. Journal of child psychology and psychiatry, 38(5), 581-586.

11. Goodman, R. (2001). Psychometric properties of the strengths and difficulties questionnaire. Journal of the American Academy of Child \& Adolescent Psychiatry, 40(11), 1337-1345.

12. Harrison, J., Vannest, K., \& Reynolds, C. (2013). Social acceptability of five screening instruments for social, emotional, and behavioral challenges. Behavioral Disorders, 38(3) 171-189.

13. Hussein, S. (2008). Behavioral problems among children attending private and community schools in Karachi, Pakistan. Pakistan Journal of Psychological Research, 23(1-2), 1-11.

14. Individuals with Disabilities Education Act, 20 U.S.C. $§ 1400$ (2004).

15. Kauffman, J., \& Landrum, T. (2013). Characteristics of emotional and behavioral disorders of children and youth (10 ${ }^{\text {th }}$ ed.). Boston, MA: Pearson.
16. Lane, K., Kalberg, J., Lambert, E., Crnobori, M., \& Bruhn, A. (2010). A comparison of systematic screening tools for emotional and behavioral disorders: A replication. Journal of emotional and behavioral disorders, 18(2). 100-112.

17. Maajeeny, H. (2018). Children with emotional and behavioral disorders in Saudi Arabia: A preliminary prevalence screening. European Journal of Special Education Research, 3(3), 49-78. Retrieved from https://oapub.org/edu/index.php/ejse/article/vie w/1550

18. Maajeeny, H. (2019). The therapeutic classroom for children with emotional and behavioral disorders. European Journal of Special Education Research, 4(4), 170-177. doi: 10.5281/zenodo.3406700

19. Moffitt, T. E., Caspi, A., Dickson, N., Silva, P., \& Stanton, W. (1996). Childhood-onset versus adolescent-onset antisocial conduct problems in males: Natural history from ages 3 to 18 years. Development and psychopathology, 8(2), 399-424.

20. Molina, B. S., \& Pelham Jr, W. E. (2003). Childhood predictors of adolescent substance use in a longitudinal study of children with ADHD. Journal of abnormal psychology, 112(3), 497.

21. Nelson, J., Benner, G., Lane, K., \& Smith, B. (2004). Academic achievement of K-12 students with emotional and behavioral disorders. Exceptional Children, 71(1), 59-73.

22. Owens, J., Storer, J., Holdaway, A., Serrano, V., Watabe, Y., Himawan, L., Krelko, R., Vause, K., Girio-Herrera, E., \& Andrews, N. (2015). Screening for social, emotional, and behavioral problems at kindergarten entry: Utility and incremental validity of parent report. School Psychology Review, 44(1), 2140.

23. Pastor, P., Reuben, C., \& Duran, C. (2012). Identifying emotional and behavioral problems in children aged 4-17 years: United States, 2001-2007. National health statistics reports, (48), 1-17.

24. Sprague, J., \& Perkins, K. (2009). Direct and collateral effects of the First Step to Success program. Journal of Positive Behavior Interventions, 11(4), 208-221.

25. Stoutjesdijk, R., Scholte, E., \& Swaab, H. (2012). Special needs characteristics of children with emotional and behavioral disorders that affect inclusion in regular education. Journal of Emotional and Behavioral Disorders, 20(2), 92-104.

26. Syed, E., Hussein, S., \& Mahmud, S. (2007). Screening for emotional and behavioral problems amongst 5-11-year-old school children in Karachi, Pakistan. Social 
Psychiatry and Psychiatric

Epidemiology, 42(5), 421-427.

27. The General Authority for Statistics. (n.d.). Retrieved October 03, 2019, from http://www.stats.gov.sa/en/node

28. Trout, A., Nordness, P., Pierce, C., \& Epstein, M. (2003). Research on the academic status of children with emotional and behavioral disorders: A review of the literature from 1961 to 2000. Journal of Emotional and Behavioral Disorders, 11(4), 198-210.

29. United Nations Educational, Scientific and Cultural Organization. (1994). The Salamanca Statement and Framework for action on special needs education: adopted by the World Conference on Special Needs Education;
Access and Quality. Salamanca, Spain, 7-10 June 1994. UNESCO.

30. Walker, H. (2004). Commentary: Use of evidence-based interventions in schools: Where we've been, where we are, and where we need to go. School Psychology Review, 33(3), 398.

31. Woerner, W., Becker, A., Friedrich, C., Klasen, H., Goodman, R., \& Rothenberger, A. (2002). Normative data and evaluation of the German parent-rated Strengths and Difficulties Questionnaire (SDQ): Results of a representative field study. Zeitschrift Fur Kinder und Jugendpsychiatrie und Psychotherapie, 30(2), 105-112. 